\title{
DETERMINATION OF WATER IN ORGANIC SOLVENTS BY FLOW-INJECTION ANALYSIS WITH KARL FISCHER REAGENT AND A BIAMPEROMETRIC DETECTION SYSTEM
}

\author{
Chen Liang*, Pavel Vácha† and Willem E. van der Linden \\ University of Twente, Department of Chemical Technology, Laboratory for Chemical Analysis, \\ P.O. Box 217, 7500 AE Enschede, The Netherlands
}

(Received 29 May 1987. Accepted 4 September 1987)

\begin{abstract}
Summary-A flow-injection system with a biamperometric flow-through detector provided with two platinum plate electrodes was tested for the determination of water with a two-component pyridine-free Karl Fischer reagent. The response was shown to be linear in the concentration range $0.03-0.11 \%$ water in methanol, ethanol or 2-propanol, with methanol as the carrier solvent. The maximum sampling frequency was about 150 samples per hr. It appeared to be possible to introduce a membrane separation step, thus allowing for the determination of water in fouled process streams. To avoid direct contact between the Karl Fischer solution and the pumping tubes, and thus extend the lifetime of the tubes, an indirect delivery system, based on replacement of the solution by pumped silicone oil, was also applied.
\end{abstract}

Since its introduction more than ten years ago, flow-injection analysis (FIA) has been widely used in many fields of chemical analysis, including the determination of water. ${ }^{1}$ Compared with batchwise Karl Fischer titrations, flow-injection has several advantages: (i) reduced reagent consumption (it is reported that 2000 determinations can be done with 1 litre of reagent), ${ }^{2}$ (ii) high sampling frequency (up to 250 samples per $\mathrm{hr}$ is possible), ${ }^{3}$ and (iii) safety in applying toxic reagents because the whole analysis proceeds in a closed system. An additional advantage sometimes observed in FIA is the increased selectivity when the analyte is accompanied by more slowly reacting components. This may happen in the determination of water. A major disadvantage is the solvent effect. It has been observed that organic solvents may affect the peak shapes, thus reducing the general analytical applicability. ${ }^{3,4}$ With regard to the determination of water by FIA, some authors have already reported on improvements of the manifold and particularly of the detection system. ${ }^{5,6}$ In the present report this same subject is raised, including the possible application of a membrane separation step.

\section{Chemicals}

\section{EXPERIMENTAL}

Two-component pyridine-free Karl Fischer reagent sol-

*Present address: Anhui University, Department of Chemistry, Hefei, Anhui, People's Republic of China.

†Present address: Department of Analytical Chemistry, Prague Institute of Chemical Technology, Prague, Czechoslovakia. utions (Merck) were used. One $\mathrm{ml}$ of the iodine in methanol solution was equivalent to $5 \mathrm{mg}$ of water. The methanol (p.a. Merck) used as the carrier stream was dried over a molecular sieve ( $3 \AA$, Merck) by standing overnight. Before use the sieve beads were dried in a furnace at $300^{\circ}$ for at least $16 \mathrm{hr}$. Standard solutions were prepared by adding demineralized water to dried methanol. The exact concentrations were checked coulometrically with a 652 KF-Coulometer (Metrohm) and Hydranal Coulomat $\mathrm{A}$ and $\mathrm{C}$ (Riedel-de Haën). All other chemicals were of analytical reagent grade.

\section{Apparatus}

The manifold is schematically depicted in Fig. 1. A peristaltic pump (Gilson, Minipuls 2) was uscd to propel the various streams. An indirect delivery system was introduced for the Karl Fischer (K.F.) solution, based on replacement of the solution by silicone oil. In this way direct contact of the pumping tubes (bore $0.5-0.6 \mathrm{~mm}$ ) and the corrosive K.F.-solution was avoided; the pumping tubes were not affected by silicone oil. In the delivery flask the K.F.-solution and the silicone oil were separated by a thin impermeable Teflon membrane. Samples were injected man-

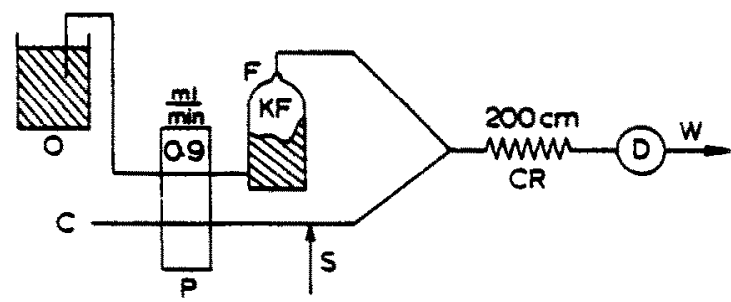

Fig. 1. Flow-injection manifold for the determination of water. P, Peristaltic pump; $C$, carrier stream; KF, Karl Fischer reagent; $F$, delivery flask; $O$, container with silicone oil; $C R$, reaction coil; $D$, detector; $W$, waste; $S$, injection valve. 


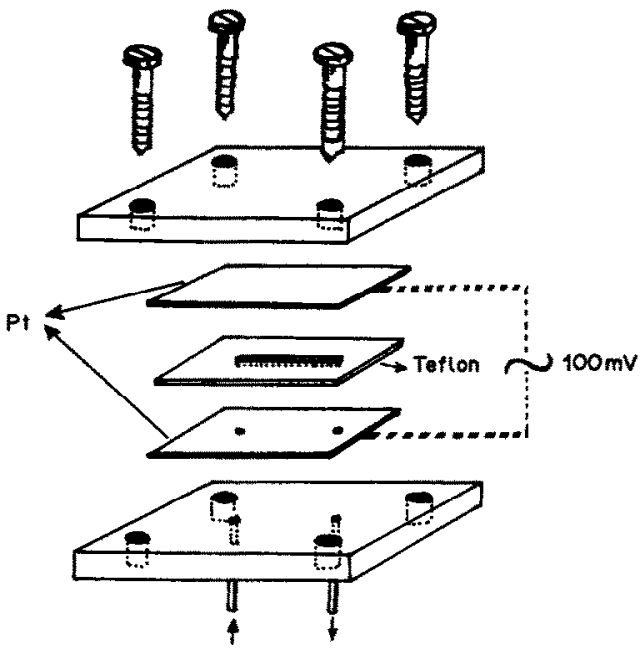

Fig. 2. Exploded view of biamperometric detector.

ually by means of a 4-way valve ( $R$ heodync) provided with a 30- $\mu 1$ sample loop. The home-made biamperometric detection cell consisted of two thin platinum plate electrodes clamped between Perspex blocks and separated by a thin Teflon spacer $(0.6 \mathrm{~mm}$ thick) with a groove of $10 \times 0.8 \mathrm{~mm}$; cell volume about $5 \mu$ ) as shown in Fig. 2. A 100-mV potential difference was applied between the two electrodes. A 585 Polarizer (Metrohm) was used as the voltage source. The output was registered on a strip-chart recorder (Kipp, BD-8). The membrane separation cell ${ }^{7}$ was provided with a hydrophilic microporous polypropylene membrane (Celgard 3501, Celanese).

\section{RESULTS AND DISCUSSION}

The mechanism of the Karl Fischer reaction has been extensively studied ${ }^{8}$ and it has been shown that the reaction goes rapidly to completion even when both reagent and water concentrations are low. Consequently, the interference of more slowly reacting concomitants can be eliminated by shortening the reaction times. By varying the concentration of the K.F.-reagent it was found that an optimum sensitivity was obtained for a $1: 8(\mathrm{v} / \mathrm{v})$ dilution of the reagent in methanol (Table 1 ).

As long as sufficient K.F.-reagent is available for the reaction with a constant amount of water, constant sensitivity would be expected. However, we have observed that mixing of the carrier and reagent streams proceeds slowly for the more concentrated K.F.-solutions. This may lead to less complete reaction and, correspondingly, to decreased sensitivity. On the other hand for highly diluted K.F.-reagent

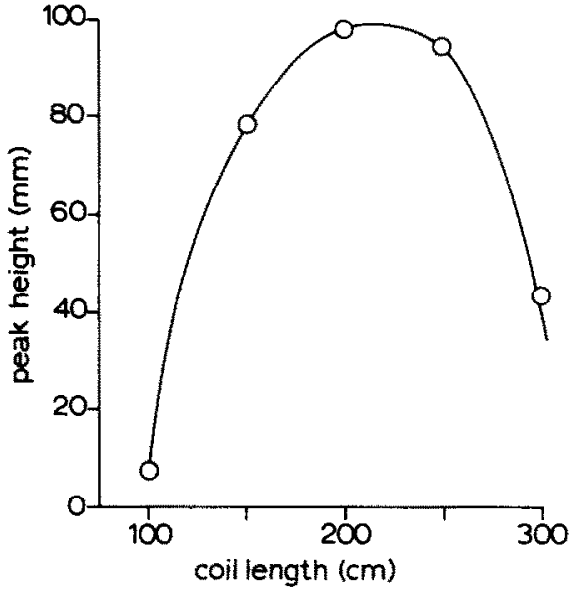

Fig. 3. Variation of peak height with reaction coil length (bore $0.5 \mathrm{~mm}$ ). Samples contained $0.119 \% \mathrm{H}_{2} \mathrm{O}$ in methanol. Flow-rate of 1:8 (v/v) diluted Karl Fischer reagent solution and carrier stream was about $0.9 \mathrm{ml} / \mathrm{min}$.

solutions the amount of reagent limits the magnitude of the signal. Therefore there is an intermediate range of K.F.-solutions concentration that is high enough to cope with the amount of water injected but low enough for the reagent and carrier streams to be sufficiently similar for mixing to be rapid.

The relation between peak height and length of the reaction coil at a fixed flow-rate is illustrated in Fig. 3. The maximum appears at $200 \mathrm{~cm}$ coil length (bore $0.5 \mathrm{~mm}$ ). Apparently, with shorter coil lengths the residence time is too short and mixing may be insufficient to ensure the reaction going to completion; with longer coil lengths the concentration sensed by the detector will decrease because of the additional dispersion. These results are in agreement with those of Kaggevall et al. ${ }^{2}$ For similar reasons the peak heights gradually decrease at flow-rates larger than about $0.8 \mathrm{ml} / \mathrm{min}$ (Fig. 4). A flow-rate of about $0.9 \mathrm{ml} / \mathrm{min}$ was selected because of the slightly better reproducibility of the peaks.

For the selected conditions (flow-rates of both reagent and carrier stream are about $0.9 \mathrm{ml} / \mathrm{min}$; coil length is $200 \mathrm{~cm}$ ) a linear calibration graph is obtained over the water concentration range $0.03-0.11 \% \mathrm{w} / \mathrm{w}$. Without a membrane separation step, water concentrations in methanol, ethanol and 2-propanol could be determined with an accuracy that compared favourably with that obtained by coulometry (Table 2). In accordance with the work of Kágevall et al. ${ }^{2}$ unsatisfactory results were obtained for samples of acetone.

Table 1. Dependence of peak height on concentration of Karl Fischer reagent*

\begin{tabular}{cccccccc}
\hline $\begin{array}{c}\text { K.F.-solution:methanol, } \\
v / v\end{array}$ & $1: 4$ & $1: 6$ & $1: 7$ & $1: 8$ & $1: 9$ & $1: 10$ & $1: 12$ \\
\hline $\begin{array}{c}\text { Peak height, } \\
\mathrm{mm}\end{array}$ & 1 & 28 & 62 & 85 & 75 & 9 & 7.5 \\
\hline
\end{tabular}

*Samples contained $0.13 \% \mathrm{H}_{2} \mathrm{O}$ in methanol; flow-rates about $0.8 \mathrm{ml} / \mathrm{min}$. 


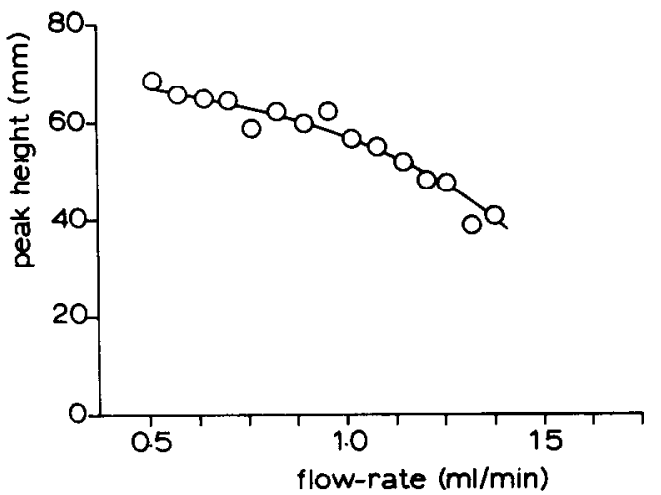

Fig. 4. Variation of peak-height with flow-rate: reaction coil length $200 \mathrm{~cm}$. Samples contained $0.119 \% \mathrm{H}_{2} \mathrm{O}$ in methanol.

Table 2. Comparison between results obtained by FIA and batchwise coulometry

\begin{tabular}{lcc}
\hline & \multicolumn{2}{c}{ Water content found, $\% w / w$} \\
\cline { 2 - 3 } Solvent & Coulometry & FIA \\
\hline \multirow{3}{*}{ Methanol } & 0.039 & 0.041 \\
& 0.041 & 0.040 \\
& 0.035 & 0.032 \\
& 0.042 & 0.041 \\
Ethanol & 0.032 & 0.027 \\
& 0.034 & 0.036 \\
& 0.028 & 0.029 \\
& 0.050 & 0.049 \\
2-Propanol & 0.033 & 0.044 \\
& 0.037 & 0.036 \\
& 0.034 & 0.029 \\
& 0.045 & 0.045 \\
\hline
\end{tabular}

If the membrane separation cell is used, the linear working range is shifted to a higher concentration level $(0.1-2 \% \mathrm{w} / \mathrm{w})$ because of the slow transport of water across the membrane.

\section{CONCLUSION}

FIA is suitable for the determination of water in methanol, ethanol and 2-propanol in the $\mu \mathrm{g} / \mathrm{g}$-range. For somewhat higher water contents a membrane separation step can be introduced, which eliminates the possibility of fouling the detection system, particularly if the sample contains solid particles. ${ }^{9}$ The biamperometric detector used in this study is simple and robust but yields unsatisfactory results for water concentrations below $0.03 \% \mathrm{w} / \mathrm{w}$.

Acknowledgements-The authors wish to express their thanks to Mr. W. Lengton, Mr. H. H. Heskamp and Ms. A. Christenhusz for their experimental help.

\section{REFERENCES}

1. J. Rủžicka and E. H. Hansen, Flow Injection Analysis, Wiley, New York, 1981.

2. I. Kågevall, O. Åström and A. Cedergren, Anal. Chim. Acta, 1980, 114, 199.

3. I. Nordin-Andersson and A. Cedergren, Anal. Chem., $1985,57,2571$.

4. I. Nordin-Andersson, O. Åström and A. Cedergren, Anal. Chim. Acta, 1984, 162, 9.

5. R. E. A. Escott and A. F. Taylor, Analyst, 1985, 110, 847.

6. H. Müller and G. Wallaschek, Z. Chem., 1984, 24, 75.

7. W. E. van der Linden, Anal. Chim. Acta, 1983, 151, 359.

8. J. C. Verhoef and E. Barendrecht, J. Electroanal. Chem., 1976, 71, 305.

9. W. E. van der Linden, Anal. Chim. Acta, 1986, 179, 91. 